\title{
Proceeding
}

\section{Effect of squash training program on health related physical fitness variables of male college students}

\author{
MOHAMMED HAMDAN HASHEM MOHAMMED \\ Physical Education Department, King Fahd University of Petroleum and Minerals, Saudi Arabia
}

\begin{abstract}
Mohammed, M.H.H. (2015). Effect of squash training program on health related physical fitness variables of male college students. J. Hum. Sport Exerc., 9(Proc2), pp.S687-S691. Squash is classified as a high dynamic exercise. Physical fitness is a measure of all functions and structures which make physical exercise possible. Health related fitness is a subset of physical fitness related to health. This study was to find out the effect of eight weeks of squash training program on heath related Physical fitness variables of male college students. A group of 141 male college students aged between 20-24 years ( $m=21.76 \pm 2.12)$ of King Fahd University of Petroleum and Minerals, Saudi Arabia participated in this study. The duration of squash training program was 45 minutes, twice a week, for 8 weeks. The following variables were measured before and after training program: Age, height, weight, body mass index, sit-ups, standing long jump, sit and reach, and 550m run. Paired t-test was used to compare before training measures with after training measures. Pre and post-test comparisons exhibited significant improvement in sit-up (20 \pm 4 vs. 23 $\pm 5 ; p<0.001), 15.8 \%$; sit \& reach (27.74 \pm 7.57 vs.30.01 $\pm 7.01 \mathrm{~cm} ; p<0.001), 8.1 \%$; standing long jump $(119.87 \pm 75.54$ vs. $129.35 \pm 80.35 \mathrm{~cm} ; \mathrm{p}<0.001), 9.7 \%$; and $550 \mathrm{~m}$ run $(2.54 \pm 1.22$ vs. $2.41 \pm 0.87 \mathrm{~min}$; $p=0.048), 5.1 \%$. However, there was no change $(p>0.05)$ in all physical characteristics variables. Squash program had a significant improvement performance on health related physical Fitness variables (sit-ups, stand long jump, sit \& reach) of male college students of KFUPM. Key words: UNIVERSITY STUDENTS, SQUASH, HEALTH-RELATED FITNESS.
\end{abstract}

Corresponding author. King Fahd University of Petroleum and Minerals, KFUPM Box 1366, Dhahran 31261, Saudi Arabia

E-mail: hamdan@kfupm.edu.sa

Asia Pacific Conference on Performance Analysis of Sport, 21-24 April 2014. Langkawi, Malaysia

JOURNAL OF HUMAN SPORT \& EXERCISE ISSN 1988-5202

(c) Faculty of Education. University of Alicante

doi:10.14198/jhse.2015.10.Proc2.07 


\section{INTRODUCTION}

Squash is classified as a high dynamic exercise. A high dynamic exercise is one which includes changes in muscle length and joint movements, in which relatively small intramuscular forces are formed during rhythmic contractions (Mitchell, Haskell, Snell \& Van Camp, 2005).

Physical fitness is a measure of all functions and structures which make physical exercise possible (Ruiz et al., 2006). It is determined mostly by physical activities and also genetic factors, though the genetic factors mostly control the effects of the physical activities performed to achieve fitness (Blair, Cheng \& Holder, 2001). Health related fitness is a subset of physical fitness related to health (Corbin, Pangrazi \& Franks, 2000) and it is composed of cardiovascular fitness, body composition, flexibility, muscle endurance, and strength (Corbin et al., 2000).

All physical exercises require the use of energy. The amount of energy stored in a body depends on the amount of energy used and the amount of energy taken in by a person. Obesity occurs when excess energy as fat is found in the adipose tissues, which can lead to diseases like coronary artery disease, diabetes mellitus and stroke (Al-Nozha et al., 2005). It was found out after a five year study by Al-Nozha et al. (2005) that Saudi males were more overweight than Saudi females, with actual figures of $42.4 \%$ and $31.8 \%$ respectively $(p<0.001)$. Overweight prevalence was found out to be $36.9 \%$ in a $95 \%$ confidence interval. The sample size for the study was 17,232 people. It was also found out by Al-Nozha et al. (2004) that out of 16,917 people who participated in the study of diabetes prevalence in Saudi Arabia, $23.7 \%$ people were diagnosed to have diabetes mellitus. They proposed the implementation of a national obesity prevention program (Al-Nozha et al., 2005) and a national prevention program for diabetes mellitus at a community level (Al-Nozha et al., 2004). The physical education program in KFUPM is a response to such a call by these researchers.

This study was to find out the effect of eight weeks of squash training program on health related physical fitness variables of male college students.

\section{MATERIAL AND METHODS}

A group of 141 male college students aged between $20-24$ years $(m=21.76 \pm 2.12)$ of King Fahd University of Petroleum and Minerals, Saudi Arabia participated in this study. The duration of the squash training program was 45 minutes, twice a week for 8 weeks. The following variables were measured before and after training program: Age, height, weight, body mass index, sit-ups, standing long jump, sit and reach, and $550 \mathrm{~m}$ run. Paired t-tests were used to compare before training measures with after training measures.

\section{RESULTS}

Table 1 shows the descriptive statistics, and the t-values and significance of paired sample tests for physical characteristics, while Table II shows the descriptive statistics, and the t-values and significance of paired sample tests for the measured pre and post parameters which evaluate health fitness. Pre and posttest comparisons exhibited significant improvement in sit-up (20 \pm 4 vs. $23 \pm 5 ; p<0.001)$, 15.8\%; sit \& reach $(27.75 \pm 7.57$ vs.30.01 $\pm 7.02 \mathrm{~cm} ; p<0.001)$, 8.1\%; standing long jump (165.57 \pm 27.25 vs. 176.63 $\pm 28.69 \mathrm{~cm} ; p<0.001), 6.7 \%$, and $550 \mathrm{~m}$ run (2.55 \pm 1.22 vs. $2.41 \pm 0.87 \mathrm{~min} ; p=0.048), 5.2 \%$. However, there was no change $(p>0.05)$ in all physical characteristics variables. 
Table 1. Descriptive Statistics and Paired Sample test of Physical Characteristics

\begin{tabular}{cccccc}
\hline Variables & $\mathrm{N}$ & \multicolumn{2}{c}{ Mean } & t-value & $p$ value \\
\hline & & Pre & Post & & \\
\cline { 3 - 5 } Age & 141 & $21.76 \pm 2.12$ & - & - & - \\
Height & 141 & $1.72 \pm 0.07$ & - & - & - \\
Body Mass & 141 & $78.52 \pm 22.86$ & $78.56 \pm 22.58$ & -0.13 & 0.895 \\
BMI & 141 & $26.29 \pm 6.95$ & $26.31 \pm 6.89$ & -0.22 & 0.826 \\
\hline
\end{tabular}

Table 2. Descriptive Statistics and Paired Sample Tests of Parameters which Evaluate Health Related Fitness

\begin{tabular}{cccccc}
\hline Variables & $\mathrm{N}$ & \multicolumn{2}{c}{ Mean } & t-value & $p$ value \\
\cline { 1 - 4 } Standing Long Jump & 141 & $165.57 \pm 27.25$ & $176.63 \pm 28.69$ & -7.45 & $<0.001$ \\
$550 \mathrm{~m}$ & 141 & $2.55 \pm 1.22$ & $2.41 \pm 0.88$ & 2.00 & 0.048 \\
Sit Ups & 141 & $20 \pm 4$ & $23 \pm 5$ & -11.08 & $<0.001$ \\
Sit and Reach & 141 & $27.75 \pm 7.58$ & $30.01 \pm 7.02$ & -7.16 & $<0.001$ \\
\hline
\end{tabular}

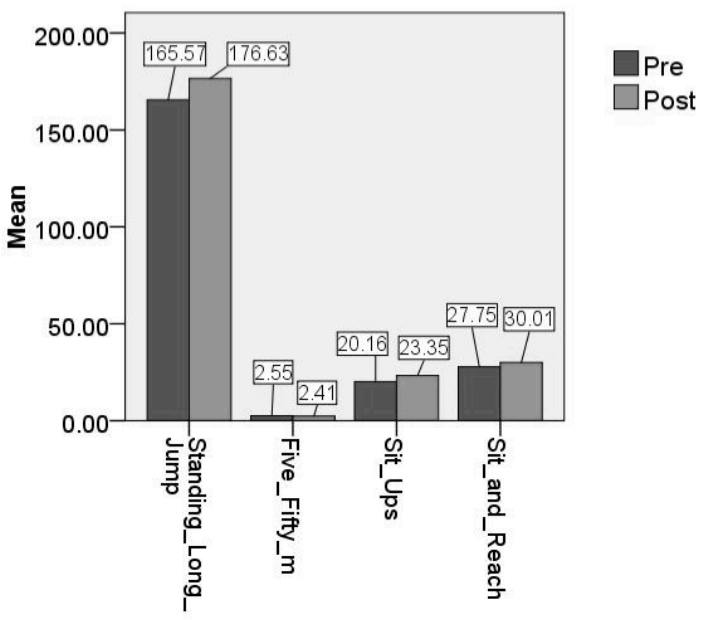

Figure 1. Mean of Pre and Post Variables

\section{DISCUSSION}

For the future health of young people, it has been recommended that they generally exercise moderately for one hour a day. In case little physical exercise is performed, doing moderate exercises for at least 30 minutes a day is recommended. It is also recommended that some exercises which focus on improving and maintaining muscular strength, flexibility and bone health needs to be done at least twice a week. (Cavill, Biddle \& Sallis, 2001).

Evidence strongly suggests that physical activity at early stages of life will be beneficial health-wise in adulthood (Ruiz et al., 2009). Physical inactivity during the early ages can be corrected in adulthood to 
prevent several chronic diseases and pre-mature deaths (Warburton, Nicol \& Bredin, 2006). Muscular fitness is also required so that people can perform daily tasks when older (Warburton et al., 2006).

The insignificant changes observed in the body mass and body mass index could be as a result of the fact that there were no major dietary changes. It has been reported that changes in diet during exercising periods can lead to a significant change in overall fat content, which will in turn affect the body mass and the body mass index values. To get a significant improvement in fat reduction, it is necessary to increase the intensity of the workout if no diet changes occur (Slentz et al., 2004). This was not the case for this program because moderate exercises were performed for 45 minutes twice a week for eight weeks.

Each improvement in exercise signifies an increase in overall health related fitness. An improvement in sit and reach shows that the students had an improved flexibility level (Ruiz et al., 2006). Improvement in sit ups shows an improvement in abdominal muscle endurance reached by the students (Koutedakis \& Bouziotas, 2003). An improvement in standing long jump shows an increase in explosive strength (Koutedakis \& Bouziotas, 2003), and an improvement in $550 \mathrm{~m}$ running time shows an improvement in cardiovascular fitness (Ruiz et al., 2006; Koutedakis \& Bouziotas, 2003). These improvements are necessary for students to be trained in the squash program, given that squash is a physical activity highly dynamic in nature. All these improvements were achieved by the students in this program, and it coincides with previous studies conducted at this same university (Ibrahim, AlAlmeer, Azeem \& Al Moslim, 2013; Mohammed, 2013). Considering that inactivity is a problem in Saudi Arabia as reported by Al-Hazzaa (2004), the above results confirm that the squash training program will enhance the health level of young Saudi adults, and inactive adults worldwide, if implemented, and continued as a habit.

\section{CONCLUSIONS}

The squash program generally had a significant improvement in performance on health related physical fitness variables (sit-ups, stand long jump and sit \& reach) of male college students of KFUPM.

\section{ACKNOWLEDGEMENTS}

The author thanks the King Fahd University of Petroleum \& Minerals, Dhahran, Saudi Arabia for financing the conference paper.

\section{REFERENCES}

1. Al-Hazzaa, H.M. (2004). Prevalence of physical inactivity in Saudi Arabia: a brief review. Eastern Mediterranean Health Journal, 10(4/5), pp.663-670.

2. Al-Nozha, M.M., Al-Maatouq, M.A., Al-Mazrou, Y.Y., Al-Harthi, S.S., Arafah, M.R., Khalil, M.Z., ... Al-Mobeireek, A. (2004). Diabetes mellitus in Saudi Arabia. Saudi Medical Journal, 25(11), pp.1603-1610.

3. Al-Nozha, M.M., Al-Mazrou, Y.Y., Al-Maatouq, M.A., Arafah, M.R., Khalil, M.Z., Khan, N.B., ... Nouh, M.S. (2005). Obesity in Saudi Arabia. Saudi Medical Journal, 26(5), pp.824-829.

4. Blair, S.N., Cheng, Y., \& Holder, J.S. (2001). Is physical activity or physical fitness more important in defining health benefits? Medicine and Science in Sports and Exercise, 33(6; SUPP), S379S399. 
5. Cavill, N., Biddle, S., \& Sallis, J.F. (2001). Health enhancing physical activity for young people: statement of the United Kingdom expert consensus conference. Pediatric Exercise Science, 13(1), pp.12-25.

6. Corbin, C.B., Pangrazi, R.P., \& Franks, B.D. (2000). Definitions: Health, Fitness, and Physical Activity. President's Council on Physical Fitness and Sports Research Digest.

7. Ibrahim, S., AlAmeer, A.H., Azeem, K., Al Moslim, H. (2013). The effect of physical education program on the physical fitness levels of the orientation students of King Fahd University of Petroleum and Minerals. Journal of Physical Education and Sport, 13(2), pp.203-208.

8. Koutedakis, Y., \& Bouziotas, C. (2003). National physical education curriculum: motor and cardiovascular health related fitness in Greek adolescents. British Journal of Sports Medicine, 37(4), pp.311-314.

9. Mitchell, J.H., Haskell, W., Snell, P., \& Van Camp, S.P. (2005). Task Force 8: classification of sports. Journal of the American College of Cardiology, 45(8), pp.1364-1367.

10. Mohammed, M.H.H. (2013). Twelve weeks study of body composition and trunk flexibility between football and squash players from pre to post test. Journal of Physical Education and Sport 13(1), pp.88-90.

11. Ruiz, J.R., Castro-Piñero, J., Artero, E.G., Ortega, F.B., Sjöström, M., Suni, J., \& Castillo, M.J. (2009). Predictive validity of health-related fitness in youth: a systematic review. British Journal of Sports Medicine, 43(12), pp.909-923.

12. Ruiz, J.R., Ortega, F.B., Gutierrez, A., Meusel, D., Sjöström, M., \& Castillo, M.J. (2006). Healthrelated fitness assessment in childhood and adolescence: a European approach based on the AVENA, EYHS and HELENA studies. Journal of Public Health, 14(5), pp.269-277.

13. Slentz, C.A., Duscha, B.D., Johnson, J.L., Ketchum, K., Aiken, L.B., Samsa, G.P., ... Kraus, W.E. (2004). Effects of the amount of exercise on body weight, body composition, and measures of central obesity: STRRIDE--a randomized controlled study. Archives of Internal Medicine, 164(1), pp.31.

14. Warburton, D.E., Nicol, C.W., \& Bredin, S.S. (2006). Health benefits of physical activity: the evidence. Canadian Medical Association Journal, 174(6), pp.801-809. 